\title{
CORREDORES DE COMERCIO JUDÍOS EN ZARAGOZA
}

(1300-1425)

\author{
ASUNCIÓN BLASCO \\ Universidad de Zaragoza
}

\section{SUMARIO}

0. Introducción.- 1. El oficio de corredor: 1.1. Designación.- 1.2. Número y proporción.- 1.3. Funciones.- 1.4. Prestigio social.- 2. Las corredurías: sus clases: 2.1. Corredores del número mayor de Veinte.- 2.2. Los corredores de oreja o de levant.- 2.3. Corredores de ropa.- 2.4. Corredores de libros.- 2.5. Corredores de animales.- 2.6. Corredores de corambre.- 2.7. Corredores (sin especificar).- 3. Conclusiones.

\section{INTRODUCCIÓN}

La situación de los corredores de comercio en la Edad Media recabó la atención primero de Torres Fontes y luego de Menjot, porque el asunto es interesante (vienen a ser los corredores de bolsa de la época) y porque se conserva una documentación del siglo XIII, relativa a los corredores murcianos, especialmente valiosa ${ }^{1}$. De los corredores judíos en Valencia y

\footnotetext{
'Juan TORRES FONTES, Los corredores del comercio murciano en el reinado de Alfonso XI, "Miscelánea Medieval Murciana", IV (1978), pp. 239-262; Denis MENJOT, Les minorités juives et musulmanes dans l'économie murcienne au Bas Moyen-Age, en "Minorités et marginaux en Espagne et dans le midi de la France (VII'-XVIII' siècles)", Paris, 1986, pp. 274 y 276-277.
}

"Anuario de Estudios Medievales", 29 (1999) 
Castellón de la Plana se ha ocupado J.R. Magdalena ${ }^{2}$. Por lo que respecta a Aragón, el tema fue tratado en 1984 por Isabel Falcón ${ }^{3}$ que centró su estudio, bien estructurado y documentado, en los corredores aragoneses durante el siglo $\mathrm{XV}$. La propia autora reconocía entonces que el asunto quedaba abierto a investigaciones futuras. Tres años después Motis publicaba un artículo sobre Los corredores judíos en Aragón en la Baja Edad Media ${ }^{4}$. Podía pensarse que el tema, por lo que a judíos aragoneses se refiere, quedaba sancionado; pero no es el caso porque, no obstante la amplitud del título, los datos que en el referido trabajo se aportan sobre Aragón son del siglo XV y, muy especialmente, de su segunda $\operatorname{mitad}^{5}$.

Por ello, me ha parecido oportuno proseguir una investigación sobre los corredores judíos de Zaragoza entre 1300 y 1425 que comencé cuando preparaba mi tesis doctoral pues, como se ha dicho, y como revelan los datos que durante años he ido registrando en el Archivo de la Corona de Aragón y en el Archivo de Protocolos de Zaragoza, la situación de los corredores judíos de esa ciudad era especial: al igual que ocurría con los notarios ${ }^{6}$, había un número determinado de corredores públicos de la ciudad (de número mayor de Veinte y de número menor de Doce o de Oreja) que los propios jurados se encargaban de controlar. Para conseguir una plaza, había que cumplir ciertos requisitos: recibir la aprobación de los dirigentes del municipio, prestar juramento, presentar avales de peso y, naturalmente, que la plaza estuviera vacante, algo que sólo se producía por muerte o

\footnotetext{
'José Ramón MAGDALENA, Juramentos de prestamistas y corredores judios en Castellón de la Plana (1441-1448), "Anuario de Filología", 3 (1977), pp. 215-223, y Prestamistas y corredores judíos de Valencia en 1342, "Miscelánea Homenaje a José M. Doñate Sebastiá", Valencia, 1993, pp. 239-252.

'María Isabel FaLcón, Notas sobre los corredores de comercio de Zaragoza en el siglo XV "Aragón en la Edad Media. Estudios de Economía y Sociedad", VI (1984), pp. 175-207.

${ }^{4}$ Miguel Angel Motis, Los corredores judios en Aragón en la Baja Edad Media, "Aragón en la Edad Media. Estudios de Economía y Sociedad", VII (1984), pp. 97-155.

${ }^{5}$ Respecto del siglo XIV, sólo se incluye una noticia sobre corredores judíos aragoneses (concretamente referida a Jaca), que se da como inédita, aunque fue publicada por Baer (Fritz BAER, Die Juden im Christlichen Spanien (en adelante JCS) Berlin, 1936 (reed. en Inglaterra, 1970), I, doc. $n^{\circ} 345$ ). El resto de la información, asimismo conocida, se refiere en buena parte a Murcia, aunque también hay datos relativos a Valencia, Barcelona, Lérida, Sevilla, Marsella y Aviñón. Amén de estos desvíos y ausencia de novedades, la mencionada publicación es confusa (por ejemplo, se mezclan los corredores de aceite con los de animales en p. 120) y superficial (así, la gráfica de los corredores de aceite se ha realizado a partir de un sólo dato: cotéjese con el punto 4).

${ }^{6}$ Asunción BLASCO, El notariado en Aragón, "Actes del I Congrés d'Història del Notariat Català", Barcelona, 1994, pp. 189-273.
} 
renuncia del que la disfrutaba. Una situación peculiar, que no solía darse en otras ciudades del reino y de los restantes territorios de la Corona.

Además de estos corredores de número, durante este período había en Zaragoza otros judíos vinculados al comercio en calidad de mediadores de ropa y joyas, de aceite, de animales, de libros, de corambre, etc. desconocidos hasta ahora y de los que he reconstruido las biografías, a veces escuetas pero firmemente documentadas, que sin duda servirán de punto de partida para otras investigaciones.

\section{EL OFICIO DE CORREDOR}

En la Edad Media el corredor desempeñaba un oficio (no cargo ${ }^{7}$ ) similar al que hoy ejercen los agentes de comercio, puesto que se encargaba de poner en relación al vendedor y al comprador. Quienes deseaban enajenar mercancías, inmuebles o instrumentos de crédito los confiaban a un corredor que buscaba clientes y los ponía en contacto con el propietario, para que entre ellos ultimaran el trato ${ }^{8}$. Este mediador fijaba el precio medio entre la oferta y la demanda. En caso de ropas o bienes muebles, solía tenerlos en depósito en su casa hasta que encontraba comprador ${ }^{9}$. En calidad de agentes comerciales entraban en contacto con personas de fuera y de la propia ciudad, lo que les permitía realizar simultáneamente varias operaciones de compraventa. Aunque no podían comerciar para sí mismos, fueron los promotores de la industria y el comercio, y gozaron del respeto de sus conciudadanos, porque en el terreno negocial gozaban de fe pública.

\subsection{Designación}

En el siglo XV la designación y nombramiento del corredor de número era competencia del concejo cristiano, puesto que se trataba de un oficio público de la ciudad. Pero no siempre se hizo así. A lo largo del siglo

\footnotetext{
${ }^{7}$ FALCÓN, Notas sobre los corredores, p. 178, 179 y 188.

${ }^{8}$ "Corredor es el que por oficio público interviene en almonedas y fuera de ellas en ajustar las compras y ventas de todo género de cosas y otras negociaciones: y porque anda casi corriendo de una parte a otra para mostrar o tratar lo que vende o negocia, se le dio este nombre": Véase Diccionario de la Lengua Castellana (de Autoridades), vol. II, pág. 608.

${ }^{9}$ Falcón, Notas sobre los corredores, p. 175.
} 
XIV, al igual que ocurrió en la designación de determinados cargos de la aljama, que era incumbencia exclusiva de ésta, el rey se arrogó dicha atribución en repetidas ocasiones y en detrimento de los jurados, tanto en Zaragoza como en Alagón, Jaca, Huesca, etc.

En los primeros años de su reinado, Pedro el Ceremonioso concedió derechos en competencia con otras jurisdicciones, tanto en la capital como en otras ciudades del reino. Así, otorgó el oficio de corredor del vino que los judíos forasteros compraban en Calatayud a Mossé Germán, judío de esa villa, de por vida, dándole la posibilidad de ejercerlo personalmente o por medio de un sustituto, como si de una renta se tratase ${ }^{10}$. La misma intencionalidad se desprende de la adjudicación vitalicia a favor de Mossé Avencanas, judío de Huesca, del oficio de "sagionie et curritorie vini et aliarum rerum" que mediante pregón se vendieran en la aljama de Hues$\mathrm{ca}^{11}$. La medida debió de despertar ciertas reticencias entre los judíos pues, pocos días después, el Soberano hacía saber a sus oficiales en esa ciudad que había nombrado corredor del vino que se vendiera en Huesca entre moros y entre judíos a Juan Gascón, miembro de su casa; aunque les advertía que el desempeño efectivo del mismo correría a cargo de un sustituto, judío para más señas ${ }^{12}$. Es curioso señalar cómo, en todos estos casos, el monarca/infante trata de revestir la designación que contra derecho realiza de las mismas formalidades que se suelen emplear en la concesión de un privilegio o en la designación de un cargo, es decir, descargando la responsabilidad, que sólo a él le incumbe, en personas de su entorno, cuyos nombres naturalmente no se especifican ("ad suplicationem quorumdam domesticorum et familiarum nostrorum... nobis factam").

Por lo que respecta a Zaragoza, donde había un numerus clausus de corredurías ( 20 en el caso de los corredores llamados de número y doce en el de los corredores de oreja o de levant), el corredor así instituido quedaba facultado por el rey para comprar y vender todos los bienes "mobilia et inmobilia ac aurum, argentum, plumbum et quodcumque metale et alia res et mercimonia ac mercaturas quascumque ad jussum et voluntatem quorucumque eas vel ea venditum ad ementium et omnia alia faciendo utendo et

\footnotetext{
${ }^{10}$ Archivo de la Corona de Aragón (en adelante ACA), reg. cancillería 951, fols. 13 r-13 v (11.I.1339).

"ACA, reg. cancillería 951, fol. 18 r. (22.I.1339).

${ }^{12} \mathrm{ACA}$, reg. cancillería 951, fol. 26 r. (5.III.1339).
} 
exercendo que dicto incumbunt oficio" en la ciudad y sus términos, percibiendo por su trabajo el salario acostumbrado ${ }^{13}$, es decir, un tanto por ciento (o comisión) llamada "correduría"14 o "corredura"15.

Algunos de estos mediadores de nombramiento real (del rey o del infante) recibían la denominación de corredores públicos generales ${ }^{16}$ y al igual que los "notarios generales" obtenían la licencia oportuna para ejercer el oficio en un marco más amplio, pues su radio de acción se hacía extensivo a "quibuscumque civitatibus, villis atque locis regnorum et terrarum dito domini regis et nostrorum"17. Previamente, el así beneficiado debía comprometerse a ejercer el oficio "bene et legaliter", bajo juramento pronunciado sobre el Libro de Moisés y los Diez Mandamientos en la propia Cancillería real ${ }^{18}$. Esta concesión era vitalicia o por el tiempo que el Monarca considerara oportuno ${ }^{19}$.

Aunque se intentaba dar la máxima apariencia de legalidad posible a estos actos, no cabe duda de que presentaban cierto carácter de arbitrariedad, y eso que a veces se alegaba la costumbre; de ahí que en el nombramiento de Açach de Palencia el Soberano ordenara encarecidamente a sus oficiales que consideraran a Açach tan corredor como cualquier otro, puesto

\footnotetext{
${ }^{13}$ Véase la concesión de Pedro el Ceremonioso a rabí Jehudá Abenlopiel, judío de Zaragoza en ACA, reg. cancillería 898, fol. 233 r (Zaragoza, 3.IV.1356).

${ }^{14}$ Ibid. Véase también ARP, Reg. 595, fol. 140 (1379).

151375.IV.25.- Açach Abenaçora, judío de Zaragoza y corredor público de dicha ciudad, reconoce que ha recibido 6 florines "por razon de mi treballo siquiere correduras" por la venta de ciertos tejidos. Archivo Histórico de Protocolos de Zaragoza (en adelante, AHPZ), Gil de Borao, 1375, fol. $48 \mathrm{r}$.

${ }^{16}$ Véase el acta otorgada por Pedro el Ceremonioso a Açach Palencia, judío de la villa de Alagón, nombrándole "cursore publicum generalem" para que pudiera ejercer el "officio curritorie generalis" y percibir el salario acostumbrado y propio de un "curritore publico et generali", quizás como subterfugio para facilitarle el acceso a una correduría en la capital de Reino (1.IV.1356), en ACA, reg. cancillería 898, fols. $224 \mathrm{v}-225$.

${ }^{17}$ Véase la concesión del infante Juan a favor de Azmel Azagez, judío de Zaragoza (10.III.1370), en ACA, reg. cancillería 1678, fol. 83 r.

${ }^{18}$ Pedro el Ceremonioso, a ruegos de algunos de sus allegados, "constituimus et creamus te, dictum Açachum [Palencia] in cursorem publicum generalem per totum regnum Aragonum predictum, ita quod in universis et singulis locis dicti Regni possis uti et utaris officio curritorie generalis quorumcumque rerum seu mercium sub salario asueto". ACA, reg. cancillería 898 , fols. 224v-225. Sobre el juramento de corredores judíos en Castellón de la Plana, véase Magdalena, Juramentos pp. 215-223. Véase también Franciso CANTERA Burgos, De cómo han de jurar los judios, "Sefarad", VII (1947), pp. 145-147.

${ }^{19}$ Véanse, respectivamente, ACA, reg. cancillería 898, fols. $224 \mathrm{v}-225 \mathrm{r}$ y 233.
} 
que había sido creado por un príncipe, al uso ("tanquam curritori a principe generaliter creato ut moris est" $)^{20}$.

Los beneficiados por el Soberano solían ser personas a las que se quería recompensar por los servicios prestados, como Jehudá Abenlopiel, de Zaragoza, que posteriormente fue nombrado rabino de la sinagoga Mayor ${ }^{21}$.

Con el paso de los años esta atribución real fue perdiendo fuerza ${ }^{22}$. En 1382 la infanta Violante, señora de la aljama de Jaca, en lugar de proceder al nombramiento de David Ambrón, judío de esa comunidad, se dirigía a los jurados jacetanos a los que rogaba, en atención al respeto y afecto que le profesaban y también a los méritos del mencionado David, tuvieran a bien concederle el oficio de corredor de la ciudad y sus términos, que le facultaría a "fer e exercir todos actos e negocios assi publicos como privados, assi de orella como otros", según costumbre ${ }^{23}$. Es decir, que poco a poco el Soberano tuvo que rendirse a la evidencia y respetar las atribuciones que de hecho y por consenso correspondían a los jurados de la ciudad $^{24}$.

En el siglo XV el nombramiento de los corredores quedó en manos de los jurados, aunque algunos de los que decidieron renunciar al disfrute de la correduría de número de la ciudad que poseían, se reservaron el derecho de buscar un sustituto adecuado, que quisiera (y pudiera) pagar el precio

\footnotetext{
${ }^{20}$ ACA, reg. cancillería 898 , fols. $224 \mathrm{v}-225$.

${ }^{21}$ Asunción BLASCO, Los judios de Aragón y los juegos de azar, "Aragón en la Edad Media", XIV-XV (=Homenaje a la profesora Carmen Orcástegui Gros), 1999, pp. 99-100.

${ }^{22}$ Sobre todo a partir de 1370. Asunción Blasco, Los judios de Zaragoza en el siglo XIV, Tesis doctoral, Zaragoza, 1987. cap. 2, vol. II, Inédito.

${ }^{23}$ Fritz BAER, JCS I, n. 345. En 1402 el converso Juan Sánchez de Calatayud reconocía que él era corredor "por virtut del sagrament por mi prestado" (AHPZ, Domingo Martín de Aguilón, 1402, fols. $28 v-29$ r).

${ }^{24}$ En 1386 Açach Abenaçora, Mossé Afia, Jentó Çaragocí y Alazar Azajez, judíos corredores de número de Zaragoza, se comprometieron ante don Juan Ximénez de Valconchán, mayordomo de los Mercaderes de esa ciudad, el notario y los testigos a decir la verdad "por la jura que ellos et cada uno dellos avian feyto a la çiudat... por la jura que feyto avian a su officio" (AHPZ, Domingo Pérez de Acelín, 1386.II.9, fols. 36 v.-37 v.). En 1402, el converso Juan Sánchez de Calatayud reconocía que él era corredor "por virtut del sagrament por mi prestado" (AHPZ, Domingo Martín de Aguilón, 1402, fols. 28 v-29 r). En 1408 Alazar Abenardut, judío de Zaragoza, que pasó a ocupar una plaza de corredor de número de dicha ciudad, vacante por renuncia de Mossé Abenabez, procedió a prestar juramento ante los mayordomos de la cofradía de Sta. María de los Predicadores en la forma acostumbrada, es decir, sobre el Libro de Moisés y los Diez Mandamientos (AHPZ, Juan de Capilla, 1408, fols. $28 v-29 r)$.
} 
exigido por la plaza vacante ${ }^{25}$. Será a raíz de las conversiones originadas por la llamada Disputa de Tortosa, cuando un rey aragonés, el Trastámara Fernando I, vuelva a inmiscuirse en las atribuciones de los jurados de Zaragoza para defender los derechos que un corredor de número de oreja de esa ciudad (el recién convertido Pedro de Casafranca) reclamaba para seguir ejerciendo el oficio que ya desempeñaba cuando se llamaba Abenardut y era judío ${ }^{26}$.

\subsection{Número y proporción}

La presencia de judíos entre los corredores de número de Zaragoza se constata ya en 1296: el 15 de diciembre de dicho año el capítulo de los jurados y hombres buenos de la ciudad autorizó a la cofradía de los Mercaderes (más conocida por la advocación de Santa María de los Predicadores), que había sido instituida en 1262 y tenía la sede en el convento de los Predicadores, para que pudiese designar veinte corredores "stablidos a huebos de la correduria de las mercaderias", a condición de que catorce fuesen cristianos y los seis restantes judíos ${ }^{27}$ : son los que posteriormente serían denominados "corredores del número mayor de Veinte de la ciudad". Naturalmente, en la cofradía no había judíos, pues los objetivos de estas asociaciones en los siglos XIII y XIV eran esencialmente piadosos ${ }^{28}$. Los judíos sólo formaban parte del número o cupo, no eran cofrades.

\footnotetext{
${ }^{25}$ Así procedió el judeoconverso Juan Sánchez de Calatayud en 1411, cuando decidió vender su correduría (AHPZ, Domingo Martín de Aguilón, 1411, fol. 89 r).

${ }^{26} \mathrm{Gemma}$ EsCRIBÁ (compiladora), The Tortosa Disputation Regesta of Dcuments from the Archivo de la Corona de Aragón. Fernando I 1412-1416, Jerusalem, 1998, doc. $\mathrm{n}^{0} 527$ (29.I.1415).

${ }^{27}$ Recoge la noticia Tomás XIMÉNEZ DE EMBÚN, Descripción histórica de la antigua Zaragoza y-de sus términos municipales, Zaragoza, 1956, p. 147. Este autor remite al "Libro de los corredores" del Archivo Municipal de Zaragoza, Arm. 24, Leg. 10, núm. 1, que al parecer se halla desaparecido. También se hacen eco de la noticia José María LACARRA, Aragón en el pasado, Madrid, 1972, p. 155, y FALCÓN, Notas sobre los corredores, p. 176.

${ }^{28}$ María Isabel FALCÓN, Ordenanzas y otros documentos complementarios relativos a las Corporaciones de oficio en el reino de Aragón en la Edad Media, Zaragoza, 1997, doc. $\mathrm{n}^{0} 27$ p. 43. Así se comprueba en el acta de una reunión de la cofradía celebrada en Zaragoza el 12 de julio de 1370. AHPZ, Domingo Pérez de Acelín, 1370, fols. $11 \mathrm{r}-12 \mathrm{r}$. Disiento por tanto de lo afirmado por Motis, en Los corredores, p. 110.
} 


\subsection{Funciones}

El corredor público podía desempeñar su función tanto en la ciudad como en sus términos ${ }^{29}$. El oficio alcanzó buena cotización en el siglo XIV, a causa de las grandes comisiones que reportaba, lo que posteriormente daría lugar a la venta, traspaso e incluso legado hereditario de corredurías ${ }^{30}$.

Constituían un cuerpo cuyo reglamento debía de ser muy estricto, pues por infringir su cumplimiento se incurría en multas de diversa consideración: así, en 1375 Açach Abenaçora fue condenado a pagar 20 florines de oro por intento de fraude en el ejercicio de la profesión ${ }^{31}$.

\subsection{Prestigio social}

Los judíos zaragozanos reconocían y valoraban la pericia de los corredores de comercio en sus transacciones monetarias, por lo que no es de extrañar que dichos individuos ocuparan cargos de responsabiblidad de la aljama, sea como adelantado (Jacob Abenalcaví, Jucé Abenarguaz, Mossé Abenabez, Salomón Moheb), albedín (Abraham Mayor) o clavario (Jehudá Golluf).

\section{LAS CORREDURÍAS: SUS CLASES}

A partir de la documentación utilizada he podido comprobar que los judíos zaragozanos desempeñaron el oficio de corredor en las modalidades siguientes: del número mayor de Veinte, de oreja (o del número menor de Doce), de ropa, de libros de animales y de corambre. En algunos casos la documentación no especifica de qué clase de corredor se trata.

\subsection{Corredores del número mayor de Veinte}

Como he dicho, el conjunto de corredores del número mayor de Veinte, o de los mercaderes, estaba integrado por veinte individuos: catorce

\footnotetext{
${ }^{29} \mathrm{ACA}$, reg. cancillería 898, fol. 233 r (Zaragoza, 3.IV.1356).

${ }^{30}$ Véase la nota 25.

${ }^{31}$ ACA, RP, 2629, fol. 40 r (1375).
} 
cristianos y seis judíos. La normativa que regulaba esta proporción fue revocada (temporalmente) en el siglo $\mathrm{XV}$, a raíz de la Constitución Apostólica de Benedicto XIII y de la Pragmática del rey Fernando $\mathrm{I}^{32}$, que prohibían a los judíos ejercer el oficio de corredor. Estas medidas segregacionistas fueron suprimidas por carta de Alfonso el Magnánimo del 21 de marzo de 1419 , disposición que hizo suya la reina María en una misiva del 8 de julio de $1420^{33}$.

El nombramiento de los corredores de número competía a los jurados de la ciudad, a propuesta de la cofradía de los Mercaderes, aunque como hemos visto el Rey usó de este derecho en más de una ocasión. Para conseguir una de las seis plazas reservadas a los judíos era preciso que alguna quedara vacante ${ }^{34}$. Estos agentes comerciales intervenían en transacciones relacionadas con toda clase de bienes muebles, inmuebles e instrumentos de crédito y por encima de todo debían actuar con honradez y ser fieles al juramento realizado antes de empezar a desempeñar el oficio ${ }^{35}$.

En 1386 se titulaban corredores de número de Zaragoza: Açach Abenaçora, Mossé Afia, Alazar Azajez y Jentó Çaragocíi ${ }^{36}$. Además, por esos años se incluían en este grupo: rabí Mossé Abenabez, Alazar Abenardut, Jehudá Abenlopiel, Jacob Cocumbriel y Açach Gallur. He aquí lo que he podido averiguar acerca de cada uno de ellos:

Abenabez, Mossé: era natural de Tudela, donde al parecer residió hasta que en la década de los años 70 se trasladó a Zaragoza ${ }^{37}$. Llevaba el título de rabí y fue talmudista, delegado de la aljama y comerciante, además de destacado poeta del círculo de Salomón de Piera. Sin duda fue uno de los

\footnotetext{
${ }^{32}$ Sobre la correcta utilización de estos términos, véase Jaume RIERA I SANS, Judios y conversos en los reinos de la Corona de Aragón durante el siglo XV, en "La expulsión de los judíos de España. II Curso de Cultura Hispano-judía y Sefardí", Toledo, 1933, p. 72, nota 135.

${ }^{33}$ BAER, JCS, no 527, pp. 847-850.

${ }^{34}$ Tal aconteció en 1408, cuando Mossé Abenabez puso su oficio a disposición de los Mayordomos de los mercaderes de Zaragoza (AHPZ, Juan de Capilla, 1408, fol. 28 v.). Véase la nota 25 .

${ }^{35} \mathrm{ACA}$, reg. cancillería 898 , fol. $233 \mathrm{r}$.

${ }^{36} 1386 . I I .9$.- Ante don Juan Ximénez de Valconchán, mayordomo de los mercaderes de Zaragoza, y en presencia de Açach Abenaçora, Jentó Çaragoçí y Alazar Azajez, "judíos corredores de numero de la dita ciudat", comparece Pedro Palomar, que había sido comisario de la aljama de judíos de Zaragoza, para pagar lo que se había tomado prestado sobre las primicias pertenecientes al Rey en el arzobispado de Zaragoza. Interrogan a Bernat Arlovín, de la casa del Rey, sobre determinados hechos ahora confusos. AHPZ, Domingo Martín de Aguilón, 1386, fols. 36 v.-37 r.

${ }^{37}$ Yitzak BAER, Historia de los judios en la España cristiana, Madrid, 1981, I, p. 354.
} 
hombres clave de la aljama zaragozana en las postrimerías del siglo XIV ${ }^{38}$ Pertenecía a la mano mayor ${ }^{39}$ y mantuvo excelentes relaciones con las familias más poderosas y ricas de la comunidad (Cavallería, Abnarrabí, Mascarán, etc.). Desde 1383 desplegó intensa actividad como prestamista. Ocupó el cargo de adelantado en diversas ocasiones y fue miembro del consejo de la comunidad repetidas veces. También formó parte del organismo directivo de la cofradía de la aljama ${ }^{40}$. Baer trata de explicar la ascensión casi meteórica de Mossé en función de las profundas transformaciones económicas y sociales que tuvieron lugar en las aljamas de judíos de Aragón a partir de la década de los años $80^{41}$. El respaldo de los Cavallería sin duda fue decisivo, pues gracias a don Benvenist (de la Cavallería) consiguió Mossé un puesto entre los corredores de número "de oro de levant (sic) de los XX de la conffraria de Santa Maria de los Predicadores, que son XIIII christianos et seys judios", al que en 1408 renunció $^{42}$. Entre 1390 y 1393 prestó servicios como corredor de número a n'Oc de Montcada, señor de Serós, recibiendo por ello una comisión del 1\% ${ }^{43}$. En 1393 fue comisionado por sus correligionarios para que defendiera ante el tesorero de la reina doña Violante los intereses de la comunidad, amenazados por nuevas imposiciones y tributos ${ }^{44}$. Poseía unas casas en la judería cerrada, junto a las de Mossé Alazar, hijo de Salomón, y a las de otros miembros de esa misma familia ${ }^{45}$. En 1399, en nombre de la aljama a la que representaba, suscribió un documento que modificaba las ordenaciones otorgadas a la misma en 1396 por Hasday Crescas ${ }^{46}$. En 1397 fue nombrado albacea de

${ }^{8}$ Ibid, p. 415.

${ }^{39} \mathrm{AHPZ}$, Jimeno de Alberuela, 1397, fol. 19 r.

${ }^{40}$ Asunción BLASCO, Instituciones sociorreligiosas judías de Zaragoza (siglos XIV-XV) Sinagogas, cofradías, hospitales, "Sefarad", 50/1 (1990), p. 16.

${ }^{41}$ BAER, Historia, I, p. 353.

${ }^{42}$ Así lo reconocía en 1408 el propio Mossé. Véase AHPZ, Juan de Capilla, 1408, fol. 28v.

${ }^{43}$ Se refiere a Odón de Serós, de Lérida. AHPZ, Juan Ximénez de Aisa, 1390, fol. 51 v. Recibió 5 florines de oro de salario por una operación que ascendió a 551 florines. Véase AHPZ, Domingo Martín de Aguilón, 1393.II.14.

${ }^{44} \mathrm{AHPZ}$, Domingo Martín de Aguilón, 1393, fols. 53 v-54.

${ }^{45}$ BLASCO, La judería, pp. 55 y 157.

${ }^{46} \mathrm{~F}$. BAER, JCS, I, n. 467, pág. 751. 
los hijos de rabí Avón Alcoquí, alias de Uncastillo, junto con algunos componentes de la familia Alazar ${ }^{47}$.

Abenardut, Alazar: era hijo de Mossé, comerciante de paños, y en enero de 1408 pasó a ocupar una de las seis plazas de corredor de número mayor de Veinte, vacante por la renuncia de Mossé Abenabez. Tras recibir el visto bueno de los mayordomos de la cofradía de Santa María de los Predicadores, prestó el juramento acostumbrado ${ }^{48}$. A raíz de los acontecimientos de Tortosa, recibió el bautismo y pasó a llamarse Pedro de Casafranca, manteniendo la correduría de número de la ciudad ${ }^{49}$.

Abenaçora, Açach: era hijo y heredero de Vidal ${ }^{50}$. El 8 de abril de 1349 había conseguido del rey Pedro el Ceremonioso la exención de impuestos vecinales, mientras que en febrero de 1363 obtuvo un salvoconducto que le garantizaba protección incluso en casos de deuda, siempre y cuando ésta no sobrepasara las 400 libras $^{51}$. Su hermana Astruga casó con un primo carnal, también llamado Açach Abenaçora, con quien no se le debe confundir, pues éste era hijo de su tío Abraham y se le llamaba "el menor" para diferenciarle de nuestro Açach el corredor, a quien en 1374 se le denominaba "el mayor"52. Fue un personaje conflictivo: acusado de tener relaciones carnales con cristianas casadas, también se le achacó el asesinato de un hijo que -se decía- había tenido con Oro, una de sus sirvientas; finalmente, fue declarado inocente de los cargos que se le imputaban ${ }^{53}$. Había contraído matrimonio con Durona, judía de Zaragoza, de la que le nació un hijo a quien pusieron por nombre $A_{b r a h a m}{ }^{54}$. Con los años, la vida conyugal de la pareja se deterioró: en 1375 Açach y Durona llegaron a un acuerdo y se separaron. Blasco de Azlor, a la sazón merino de Zaragoza, dio permiso a Açach para que viviera con otra mujer, Fazbueña;

\footnotetext{
${ }^{47} \mathrm{AHPZ}$, papeles sueltos 1397.II.6.

${ }^{48}$ Véase la nota 24.

${ }^{49} \mathrm{AHPZ}$, Antón Ximénez del Bosch, 1417, fols. 179 r-179 v.

${ }^{50} \mathrm{AHPZ}$, Sancho de Jaca, 1361.VIII.13.

${ }^{51}$ AHPZ, Sancho de Jaca, 1361.I.15, fols. 50-51 y ACA, reg. cancillería, 1181, fol. $94 \mathrm{v}$.

${ }^{52} \mathrm{AHPZ}$, Domingo Martín de Aguilón, 1384.I.12, fol. $11 \mathrm{r}$ y Vicente Rodiella, 1374, fols. $80 \mathrm{r}-84 \mathrm{v}$

${ }^{53} \mathrm{ACA}$, reg. cancillería 903 , fols. 246 v.-247 r (1360.I.20) y reg. 1175 , fols. $117 \mathrm{v}$. (1361.III.24) y 154 v.-155 r. (1361.IV.8). Ap. I.

${ }^{54}$ Manuel SERRANO y SANZ, Orígenes de la dominación española en América, Madrid 1918,
} 
pero no le concedió licencia para que se casara con ella mientras viviera su legítima esposa, en atención al contrato matrimonial que habían suscrito. Con Durona había tenido otro hijo, Jehudás5. La actividad profesional de Açach experimentó un fuerte impulso tras el fallecimiento de su padre. En torno a los años 1367-79 trabajó para don Vidal de la Caballería y para el infante don $\mathrm{Juan}^{56}$. Fue pillado en fraude en un negocio que en 1375 sostuvo con Açach Ravalla, por lo que tuvo que pagar una multa de veinte florines de oro ${ }^{57}$. En 1380 don Juan Ximénez de Valconchán, mayordomo de la cofradía de los Mercaderes de Zaragoza, recabó su presencia y la de otros tres corredores de número de Veinte de la ciudad, con el fin de investigar acerca de las irregularidades cometidas en la administración de una elevada suma de dinero que había sido tomada en préstamo sobre las primicias que el Rey poseía en el arzobispado de Zaragoza ${ }^{58}$. Su defunción tuvo lugar entre el 1 de julio de 1393 y el 18 de agosto de 1394, día en que su esposa Durona afirmaba ser viuda ${ }^{59}$.

Abenlopiel, rabi Jehudá: documentado por vez primera en los protocolos notariales de Zaragoza de $1335^{60}$, estaba casado con Jamila ${ }^{61}$ y gozaba del favor real: como he dicho, en 1356 Pedro el Ceremonioso le concedió la posibilidad de ejercer el oficio de corredor en Zaragoza y sus términos, con todas las ventajas inherentes al oficio ${ }^{62}$. Posteriormente y por designación real, fue rabí de la sinagoga Mayor de la ciudad, lo que suscitó las protestas de algunos de sus correligionarios y muy especialmente de la familia Alazar ${ }^{63}$.

Afia, Mossé: en 1367 era corredor público y, como tal, estuvo al servicio de la tesorería del rey don Pedro y del infante don Juan ${ }^{64}$. Algunos

\footnotetext{
${ }^{55}$ AHPZ, Juan Blasco de Azuara, 1399, fols. 450 r-450 v.

${ }^{56}$ Véanse, respectivamente, AHPZ, Vicente Rodiella, 1374 , fols. 80 r- 84 v y ACA, RP, 591 , fol. 103 v (2) y 595 , fol. 140 (1).

${ }^{57}$ Es decir, 108 sueldos jaqueses. Véase la nota 31.

${ }^{58} \mathrm{AHPZ}$, Pedro de Carlos, 1386, fols. 36 v. -37 r.

${ }^{59} \mathrm{AHPZ}$, Domingo Martín de Aguilón, 1393.VII.1 y 1394.VIII. 18.

${ }^{60} \mathrm{AHPZ}$, Juan Pérez del Postigo, 1335, fols. 30 r-30 v.

${ }^{61} \mathrm{AHPZ}$, Sancho de Ejulve, 1355.VIII.4.

${ }^{62}$ Véase la nota 13.

${ }^{63}$ BAER, JCS, I, n ${ }^{\circ} .269$, pág. 386.

${ }^{64}$ ACA, R.P. 353 , fol. 124 v. (1367) y 591, fol. 103 v. (1375). Además, véase AHPZ, Vicente Rodiella, 1374.III.22.
} 
comerciantes de paños le confiaron el peritaje de partidas de tejidos ingleses que resultaron defectuosas ${ }^{65}$. En 1386 Mossé Afia era corredor de número de Zaragoza ${ }^{66}$. En 1381, junto con Jacob Abenalcaví y rabí Açach Abulfada contrajo una deuda de 575 sueldos jaqueses con Botín del Bosch y su mujer, deuda que en julio de 1394 todavía no había sido saldada. ${ }^{67}$ Es posible que su hijo Salomón, habido con $\mathrm{Sol}^{68}$, siguiera su misma profesión, aunque no queda constancia de ello. Residía en la judería cerrada, en unas casas contiguas a las del pañero Imano Gallipapa ${ }^{69}$. Desplegó actividad en el seno de la cofradía de Bicorolim o de visitar los enfermos, de la que fue procurador $^{70}$.

Azajez $^{71}$, Alazar: en 1362 era corredor de Zaragoza ${ }^{72}$. Catorce años después de nuevo aparece documentado como tal en la ciudad ${ }^{73}$; en 1386 formaba parte del grupo de veinte corredores de número ${ }^{74}$. Su mujer, Jamila Abenforna, le dio al menos dos hijos: Salomón ${ }^{75}$ y Jacob, quien, en los años que siguieron a los alborotos de 1391, tras diversas vacilaciones, acabó renunciando a la religión de sus mayores ${ }^{76}$. Poseía unas casas en el barrio judío (situadas junto a las de Jehudá Ceha, Jucé Trigo y Alazar Golluf) que en cierta ocasión le fueron embargadas por no haber satisfecho una deuda a su debido tiempo ${ }^{77}$. Su muerte se produjo con anterioridad al 5 de enero de 1389 , pues así se hace constar en un acta notarial celebrada

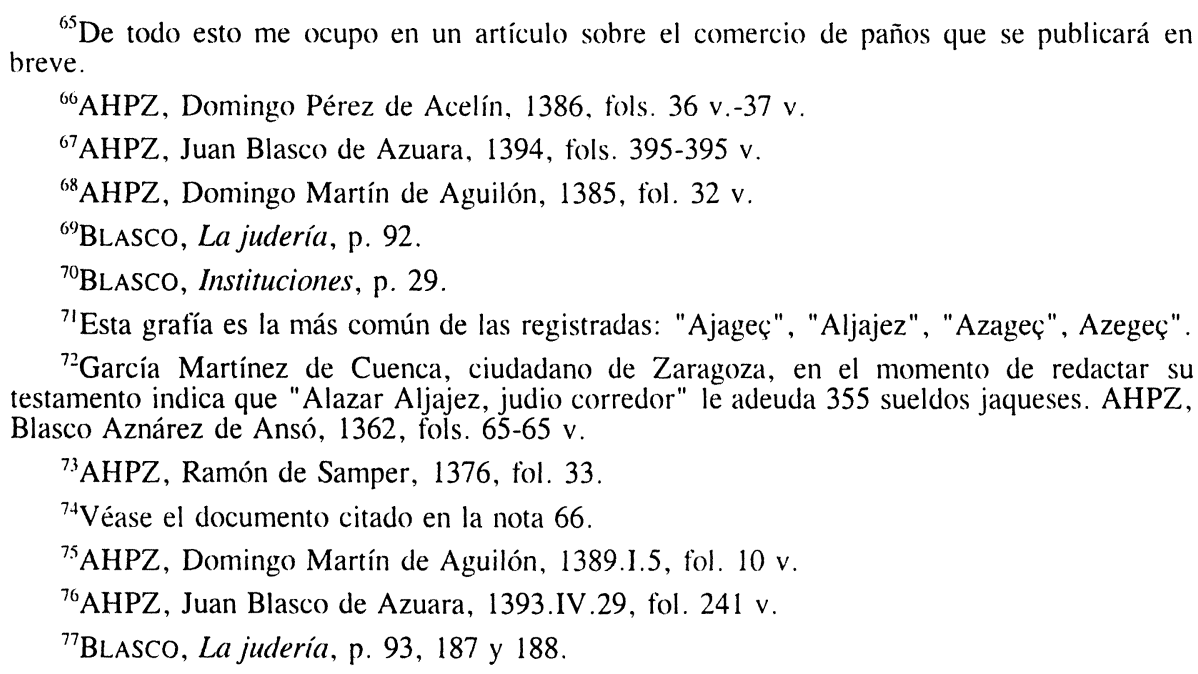

${ }^{65}$ De todo esto me ocupo en un artículo sobre el comercio de paños que se publicará en

${ }^{60} \mathrm{AHPZ}$, Domingo Pérez de Acelín, 1386, fols. 36 v.-37 v.

${ }^{67} \mathrm{AHPZ}$, Juan Blasco de Azuara, 1394, fols. 395-395 v

${ }^{68} \mathrm{AHPZ}$, Domingo Martín de Aguilón, 1385, fol. $32 \mathrm{v}$.

${ }^{69}$ BlasCo, La judería, p. 92.

${ }^{70}$ Blasco, Instituciones, p. 29.

"Esta grafía es la más común de las registradas: "Ajageç", "Aljajez", "Azageç", Azegeç".

${ }^{72}$ García Martínez de Cuenca, ciudadano de Zaragoza, en el momento de redactar su testamento indica que "Alazar Aljajez, judio corredor" le adeuda 355 sueldos jaqueses. AHPZ, Blasco Aznárez de Ansó, 1362, fols. 65-65 v.

${ }^{73} \mathrm{AHPZ}$, Ramón de Samper, 1376, fol. 33.

${ }^{74}$ Véase el documento citado en la nota 66.

${ }^{75} \mathrm{AHPZ}$, Domingo Martín de Aguilón, 1389.1.5, fol. $10 \mathrm{v}$.

${ }^{76} \mathrm{AHPZ}$, Juan Blasco de Azuara, 1393.IV.29, fol. $241 \mathrm{v}$.

${ }^{77}$ BLASCO, La judería, p. 93, 187 y 188. 
dicho día y referida a su hijo Salomón ${ }^{78}$. El 11 de marzo de 1390 su viuda se vió obligada a hipotecar parte de sus casas a Iosuas Francés, hijo de Jucé, judío de Zaragoza, a quien adeudaba 1.000 sueldos jaqueses $^{79}$.

Ajazez, Azmel: que en 1370 recibió licencia del infante don Juan para ejercer su oficio de corredor en todos los territorios del Rey, como "curritor publico" 80.

Cocumbriel $^{81}$, Jacob: la primera noticia registrada en los protocolos notariales sobre Jacob Cocumbriel data de $1381^{82}$. Era corredor de número de Zaragoza ${ }^{83}$. Se unió a su hermano Jentó (pellicero) y a otros judíos de la aljama para solicitar créditos a varios cristianos ${ }^{84}$. No sé cuándo empezó a ejercer el oficio de corredor, pero sería antes de $1397^{85}$. Con el corredor de oreja Jucé Abenarguaz trabajó a las órdenes de Juan Dum, de la tesorería del rey don Martín ${ }^{86}$. En 1399 intervino en un litigio sobre paños importados que presentaban taras ${ }^{87}$. Poseía unas casas en el callizo Primero de la judería nueva, contiguas a lás de Mayr Acrix y a las de Jentó Nazir ${ }^{88}$. Se puede concluir que Jacob Cocumbriel pertenecería al estamento social mediano. Se conserva su firma autógrafa en caracteres hebreos ${ }^{89}$.

Gallur, Açach: era corredor de número a comienzos del siglo $\mathrm{XV}$, pero en 1416 perdió la plaza, al entrar en vigor la pragmática del rey Fernando que prohibía a los judíos ejercer el oficio de corredor ${ }^{90}$.

\footnotetext{
${ }^{78} \mathrm{AHPZ}$, Domingo Martín de Aguilón, 1389, fol. $10 \mathrm{v}$.

${ }^{79}$ BLASCO, La judería, p. 93, nota 502.

${ }^{80}$ Véase la nota 17.

${ }^{81}$ Además de esta grafía se dan otras: "Cogubriel", "Cogumbriel", "Cucumbriel" y "Alcugumbriel".

${ }^{82} \mathrm{AHPZ}$, Domingo Martín de Aguilón, 1381, fols. 85 r-85 v.

${ }^{83} \mathrm{AHPZ}$, Juan de Capilla, 1405, fols. $198 \mathrm{v}-199 \mathrm{r}$.

${ }^{84} \mathrm{AHPZ}$, Juan Blasco de Azuara, 1396, fol. 295 r, 1399, fols. 389 r-389 v y Juan López de Barbastro, 1400, fols. 132 v. -133 r

${ }^{85} \mathrm{AHPZ}$, Vicente Rodiella, 1397, fols. 68 r-68 v. y Juan López de Barbastro, 1397, fols. 143 v. $-144 \mathrm{r}$

${ }^{86} \mathrm{AHPZ}$, Pedro de Carlos, 1398, fols. 83 v-84 r.

${ }^{87} \mathrm{Me}$ ocupo de ello en un estudio que actualmente preparo.

${ }^{88}$ BlasCo, La judería, p. 108.

${ }^{89} \mathrm{AHPZ}$, Juan López de Barbastro, 1397, fols. 143 v.-144 r.

${ }^{90}$ En su lugar, entró Alfonso de Ferrera. AHPZ, Antón Ximénez del Bosch, 1416, fols. 148 $\mathrm{v}-149 \mathrm{r}$.
} 
Çaragocí, Jentó: en torno al año 1355 había alcanzado la mayoría de edad y gozaba de plena personalidad jurídica, era sastre y solía asistir a las asambleas plenarias de la aljama ${ }^{91}$. En torno a 1385 se observa un notable cambio - ¿quizás era un homónimo?-, pues sustituye la aguja por las transacciones comerciales y los préstamos, que paulatinamente monopolizaron su actividad ${ }^{92}$. En 1386 era corredor de número del grupo mayor de Veinte de la ciudad ${ }^{93}$. Testificó algunos documentos relacionados con compañeros de profesión ${ }^{94}$ y en 1393 desempeñó el cargo de mayordomo de la cofradía de la almosna de la aljama ${ }^{95}$. Trabajó en diversas ocasiones junto con Mossé Afia, asimismo corredor de número" ${ }^{96}$, y en 1395 se querelló con Martín Catalán ${ }^{97}$. Intervino como acreedor y como intermediario en numerosos contratos de préstamo y comanda, que sería largo pormenorizar aquí. En 1397 era consejero de la aljama ${ }^{98}$. No he conseguido averiguar si de su matrimonio con Bonafilla le nacieron hijos varones, aunque todo parece indicar que no fue así; si los tuvo, lo más seguro es que no le sobrevivieran. Me consta que tuvo una hija, Dueña Çaragoçí, casada con el pañero Salomón Abenaçaya, que fue su heredera universal ${ }^{99}$. El fallecimiento de Jentó se produjo entre el 28 de noviembre de 1399 y el 18 de marzo de $1401^{100}$. Su herencia pasó después a su nieto Jentó Abenaçaya, hijo de los citados Salomón y Dueña ${ }^{101}$.

\footnotetext{
${ }^{91}$ AHPZ, Sancho de Ejulve, 1355.VIII.4, Juan de Capilla, 1360, fol. 244 r.

${ }^{92}$ AHPZ, Domingo Martín de Aguilón, 1385.I.18, 23 y 25, III.24, IV.17, VIII.11 y IX.26.

${ }^{93}$ AHPZ, Domingo Pérez de Acelín, 1386.II.9, fols. 36 v.-37 r.

${ }^{94}$ Como Jacob Almalcaví y Mossé Afia. AHPZ, Juan Blasco de Azuara, 1389, fol. $260 \mathrm{v}$.

${ }^{95}$ BLASCO, Instituciones, p. 16.

${ }^{96}$ Véanse los datos biográficos de dicho personaje, ya estudiado.

${ }^{97}$ Teniendo que recurrir a un juez árbitro. AHPZ, Juan Blasco de Azuara, 1395, fol. 500r.

${ }^{98} \mathrm{AHPZ}$, Juan Blasco de Azuara, 1398, fols. 286 v-287 r.

${ }^{99} \mathrm{AHPA}$, Juan Blasco de Azuara, 1402, fols. 29 v. -30 r.

${ }^{100} \mathrm{AHPZ}$, Jimeno de Alberuela, 1399, fols. 144 r-144 v y Domingo Martín de Aguilón, 1399, fols. 72 v. $-73 \mathrm{r}$.

${ }^{101}$ AHPZ, Juan Blasco de Azuara, 1402, fols. 29 v. -30 r.
} 


\subsection{Los corredores de oreja o de levant}

Los corredores de oreja o "de levant"102 o del número menor de Doce ${ }^{103}$ realizaban un trabajo similar al de los corredores de número, de los que se diferenciaban porque, en teoría, sólo podían negociar con treudos y censales. Solicitaban dinero prestado para hombres de negocios y ajustaban tanto los cambios o intereses que se habían de dar como sus seguridades y resguardos. Según parece, este grupo de doce corredores también estaba integrado por cristianos y judíos aunque se desconoce su proporción ${ }^{104}$. Su nombramiento dependía directamente de los jurados ${ }^{105}$.

En el siglo XIV fueron corredores de oreja o de levant en Zaragoza: Jucé Abenarguaz, Ezdra Alazar, Mossé Moçachón y Zecrí Pinaz. Veamos cada uno de ellos.

Abenarguaz, Jucé: La primera mención contenida en los protocolos zaragozanos sobre él es del 9 de octubre de $1390^{106}$. Por entonces Jucé se hallaba inmerso en negocios que le llevaron a la ruina ${ }^{107}$. No obstante, consiguió salvar este bache, posiblemente gracias a su oficio de corredor, pues desde 1393 y en diversas ocasiones se requirieron sus servicios para dirimir algunos de los litigios ocasionados al recibirse géneros textiles de importación defectuosos ${ }^{108}$. Intervino en varias transacciones comerciales ${ }^{109}$ y estuvo al servicio de destacados personajes de la corte ${ }^{110}$. Era miembro del consejo de la aljama por la mano mediana y gozaba de tal prestigio entre sus correligionarios que en 1397 los de su estamento le

\footnotetext{
${ }^{102}$ Así se hace constar en un acta notarial de 1361 en la que se dice que Zecrí Pinaz era "corredor de aure de levant" de Zaragoza (AHPZ. Simón de Capilla, 1361, fols. 235 v.-236 r) y de otros textos publicados por Baer en los que se dice que Salvat Natham era "curritor mercium de levant" en Barcelona (BAER, JCS, I, p. 410) y que Jucé Abraham ejercía el oficio de "curritor auris (oris de levant)" en esa ciudad (ibid, p. 412).

${ }^{103}$ FALCÓN, Notas sobre los corredores, pp. 181-182.

${ }^{104}$ Ibid., p. 181.

${ }^{105}$ FALCón, Ordenanzas, n 172 , pp. 392-395.

${ }^{106} \mathrm{AHPZ}$, Juan Ximénez de Aisa, 1390, fol. $120 \mathrm{v}$.

${ }^{107} \mathrm{AHPZ}$, Domingo Martín de Aguilón, 1391.VIII.16, fol. $163 \mathrm{v}$.

${ }^{108} \mathrm{Me}$ ocupo de ello en un estudio sobre el comercio de paños que está en fase de elaboración.

${ }^{109} \mathrm{AHPZ}$, Domingo Martín de Aguilón, 1394.III.10.

${ }^{110}$ Trabajó con Cocumbriel al servicio de Juan Dum, de la tesorería del rey don Martín. Véase la nota 86.
} 
comisionaron para la tasación de la talla del regimiento ${ }^{111}$. Dos años después desempeñaba el cargo de adelantado ${ }^{112}$. En las postrimerías del siglo XIV se vio privado de libertad por solidarizarse con su hijo Abraham, que (con otros dos judíos de Zaragoza) había concedido a Guillermo de Celma un crédito de 50 florines de oro sobre una vestimenta ("hopa") de damasco que éste había robado a su señor mosén Gil de Pueyo ${ }^{113}$. Tuvo otro hijo, Açach, a quien en octubre de 1399 otorgó plenos poderes para que pudiera pleitear por él ${ }^{114}$. Habitaba en la judería cerrada, en unas casas todavía sin localizar, contiguas a las de Jehudá Abenaçora y su mujer Mira Albalá115. En diversas actas notariales del año 1400 se hace constar que era "corredor de orella de Çaragoça" y se recoge su firma autógrafa en caracteres hebreos ${ }^{116}$.

Alazar, Ezdra: era descendiente del gran físico Alazar, nieto de Ezdra Alazar e hijo del también físico Alazar Abnalazar y de Falima (hija de Çaçón Catorce, judío de Teruel) ${ }^{117}$. Miembro de una de las familias zaragozanas más influyentes, emparentó con la familia Abentilca, de Calatayud, al casar con doña Mira Abentilca o "Mira don Todroz"118. Corredor de oreja ${ }^{119}$, entabló negociaciones con Juan Don Sancho, conocido financiero cristiano, que en 1394 le arrendó por un período de dos años la marca de los tres dineros por libra que se recaudaban en Aragón, según consta en el contrato realizado ante el notario Juan de Lodosa ${ }^{120}$. Prestó sus buenos oficios a la Diputación General de Reino ${ }^{121}$ y cuando, en junio de 1397, la salud de su padre se volvió precaria a causa de su avanzada

"'AHPZ, Jimeno de Alberuela, 1397, fols. 64 v-65 v.

${ }^{112} \mathrm{AHPZ}$, Domingo Martín de Aguilón, 1399, fols. 59 v-60 r.

${ }^{113}$ AHPZ, Domingo Martín de Aguilón, 1399, fol. 55 r.

${ }^{114}$ AHPZ, Domingo Martín de Aguilón, 1399, fol. 51 v.

${ }^{115}$ BLASCO, La Judería, p. 91.

${ }^{116} \mathrm{AHPZ}$, Juan de Capilla, 1400 , fols. 10 r, 72 v. -73 r y 73 v. -74 r.

${ }^{117}$ AHPZ, Domingo Martín de Aguilón, 1398, fols. 57 r-57 v. $224 \mathrm{v}$.

${ }^{118}$ AHPZ, Juan Ximénez de Aisa, 1390, fol. 124 y Domingo Martín de Aguilón, 1395, fol.

${ }^{119} \mathrm{AHPZ}$, papeles sueltos, 1392.IV.27.

${ }^{120} \mathrm{Se}$ inserta la noticia en AHPZ, Simón de Capilla, 1396, fol. 2 r. Sobre la intervención de los corredores en el cobro de impuestos, véase Alberto GaRcía UlECIA, El papel de los corredores y escribanos en el cobro de las alcabalas, "Historia. Instituciones. Documentos", 13 (1986), pp. 89-110.

${ }^{121} \mathrm{AHPZ}$, Juan de Raro, 1396, fols. 148 r-149 r y 217 r-217 v. 
edad, se hizo cargo de sus asuntos económicos ${ }^{122}$. Por decisión del Castellán de Amposta, heredó los derechos que su padre había disfrutado en vida sobre un campo ubicado en La Huerva, treudero a la Orden del Hospital en 20 sueldos jaqueses anuales ${ }^{123}$.

Moçachón, Mossé, alias Mentira: aparece documentado en los protocolos notariales de Zaragoza desde $1377^{124}$. En 1391 había contraído matrimonio con Mira Castillo, ocasionalmente llamada de Fuentes ${ }^{125}$. He podido comprobar que era "corredor de levant" en tres actas notariales de junio de 1393 relacionadas con Astruch Alcolumbre y su hijo Abraham, judíos de Zaragoza, que fueron testificadas por él ${ }^{126}$. En la parroquia de San Miguel poseía una dependencia ("cambra"), que lindaba con casas de Reina la Guaxquia y Mossé Abenarama ${ }^{127}$. Era amigo personal del zurrador Pedro Sánchez de Monterde, con quien se solidarizó para endeudarse con Martín de la Mula ${ }^{128}$. Intervino en numerosos negocios con cristianos, entre los que figuran Domingo Calvo y Blasco Soro de Tolosana ${ }^{129}$. Era amigo del pellejero Samuel Sucra, judío de Zaragoza, a quien avaló en algún negocio contratado por ambos ${ }^{130}$.

Pinaz, Zecrí: documentado en Zaragoza por vez primera en $1347^{131}$, en 1361 ejercía el oficio de "corredor de aure de levant" de esa ciudad $^{132}$. Actuó como testigo en algunas actas notariales y en 1366 fue

\footnotetext{
${ }^{122}$ AHPZ, Domingo Martín de Aguilón, 1397.VI.12, fols. 48 v.-49.

${ }^{123}$ Se conserva el albarán de 1399 en AHPZ, Miguel de Canfranc, 1399.V.3, fol. 38 r.

${ }^{124}$ Además de "Moçachon", se dan las grafías "Moçagon" y "Açachon". Respecto del sobrenombre ("alias Mentiras"), véase AHPZ, Juan Blasco de Azuara, 1393, fol. 205 v, 1394. fol. 152 v. y 1399, fol. 412 v.; y Pedro Aznárez de Ansó, 1398, fol. 10 r.

${ }^{125}$ AHPZ, Domingo Martín de Aguilón, 1391, fol. 161 v. y Juan Blasco de Azuara, 1392, fol. 331 v. Sobre el alias "de Fuentes", véase AHPZ, Ramón Amat, 1393, fol. 187 r.

${ }^{126} \mathrm{AHPZ}$, Juan Blasco de Azuara, 1393, fols. 376 r, 381 v. y 382 r.

${ }^{127}$ BLASCO, La judería, p. 131.

${ }^{128} \mathrm{AHPZ}$, Domingo Martín de Aguilón, 1394.I.5, fols. 5 r-5 v. $163 \mathrm{r}$.

${ }^{129} \mathrm{AHPZ}$, Pedro Aznárez de Ansó, 1398, fol. 10 r y Juan Blasco de Azuara, 1398, fol.

${ }^{130} \mathrm{AHPZ}$, Juan Blasco de Azuara, 1394, fols. 211 v. $-212 \mathrm{r}$ y 1399 , fol. 412 v. Véase también Archivo Municipal de Zaragoza, Juan Blasco de Azuara, 1397, fol. 173 r.

${ }^{131} \mathrm{AHPZ}$, Pedro Sánchez de Monzón, 1347, fol. $32 \mathrm{r}$.

${ }^{132}$ AHPZ, Simón de Capilla, 1361, fols. 235 v-236 r.
} 
adelantado de la aljama $^{133}$. Estaba casado con Dueña Abenforna ${ }^{134}$ y debió de morir antes del mes de octubre de $1374^{135}$.

\subsection{Corredores de ropa}

A mediados del siglo XV los corredores de ropa de Zaragoza constituían un grupo de veinte miembros entre los que había dos judíos ${ }^{136}$. Recibían géneros en depósito para gestionar su venta. Traficaban con toda clase de ropas nuevas y usadas, de vestir y para el hogar, sin olvidar las joyas y enseres domésticos. Los corredores de ropa podían ser mujeres: es el caso de China, la esposa de Benay Francés, que en 1360 trabajaba como intermediaria para la reina Leonor ${ }^{137}$, y de Sol, "corredera" domiciliada en Zaragoza en $1356^{138}$; aunque era más frecuente que fueran varones.

En el siglo XIV se registran en Zaragoza varios corredores de ropa judíos: Samuel Fichel, Abraham Mayor, Bonafós Mayor y Jucé Surí. Dos de ellos formaban parte de una misma familia y al menos tres eran juglares. También traficaba con ropa y joyas la citada China Francés.

Fichel, Samuel: en 1379 se registra en Zaragoza la presencia de un judío llamado Samuel -el apellido se desconoce- que ejercía la doble actividad de "juglar et corredor de ropa". Me atrevo a aventurar que se trata de Salomón Fichel, registrado por estos mismos años en Zaragoza, y que está documentado como juglar y como corredor ${ }^{139}$.

Francés, China (o Gina): esposa de Benay (Menahem) Francés ${ }^{140}$, en 1360 era "corredora"141. Trabajó al servicio de la reina doña Leonor,

\footnotetext{
${ }^{133}$ AHPZ, Sancho Martínez de la Peira, 1367.IV.5 y Gil de Borao, 1365, fols. 118 r-118 v. Véase también ACA, RP, 35, fol. 33 r (1366).

${ }^{134} \mathrm{AHPZ}$, Domingo Pérez de Acelín, 1377, fols. 75 r-75 v.

${ }^{135}$ AHPZ, Domingo Pérez de Acelín, 1376, fol. 119 v.

${ }^{136}$ FalCón, Notas sobre los corredores, p. 184 (nota 47).

${ }^{137}$ Véase más adelante su breve biografía.

${ }^{138} \mathrm{AHPZ}$, Pedro Loarre, fols. 2 r-2 v.

${ }^{13.9}$ Sobre este personaje, véase Asunción BLASCO, Jewish and convert jongleurs, minstrels and "sonadores" in Saragossa (fourtheenth and fifteenth centuries), "Orbis Musicae" (Tel Aviv University), XII (1998), pp. 51-52.

${ }^{140} \mathrm{AHPZ}$, Blasco Aznárez de Ansó, 1362, fol. 72 r.

${ }^{141}$ En 1360 el tesorero de la reina Leonor abonaba a Gina Francesa "juya corredora de Saragoça" lo que se le debía por una alfarda de seda (ACA, RP, 475, fol. 61 r). Un año después, la mencionada Gina, judía corredora de Zaragoza, cobraba de la tesorería de la Reina
} 
siendo retribuida por eso. Tanto ella como su marido Benay estaban exentos de impuestos: cuando Benay murió, el rey don Pedro ordenó que China siguiera difrutando de la franquicia concedida al difunto, beneficio que en 1391 confirmó la reina Violante ${ }^{142}$. Residía en la judería cerrada, cerca de la puerta Finera ${ }^{143}$.

Mayor, Abraham: la primera noticia sobre Abraham Mayor recogida en los protocolos notariales de Zaragoza data de 1377 y lo registra como juglar. En 1384 Abraham era acreedor de Lop del Abad, habitante en Azuara y albedín ${ }^{144}$. Intervino en diversos negocios, como mediador y fiador ${ }^{145}$. En 1399 Abraham Mayor, "corredor publico et jurado de Çaragoça" pasaba a formar parte de la casa real ${ }^{146}$. A comienzos del siglo $\mathrm{XV}$ era "corredor de ropa et argent"147, es decir, de prendas de vestir y para el hogar, y joyas. En 1409 intervino en la venta de "una maça... de portero la qual havia la cabeça d.argent et la verga cubierta d.argent"148

Mayor, Bonafós: supo compaginar el arte de la juglaría con otras actividades más prosaicas: así, en septiembre de 1389 se le califica de "corredor"149, y en un documento del mes de marzo de 1394 se constata ya su condición de "corredor publico de ropa de la dita ciudat" ${ }^{150}$. Casado con Jamila Alcalahorri, entre sus propiedades figuran unas casas situadas en la judería cerrada, próximas a la iglesia de san Andrés ${ }^{151}$.

\footnotetext{
el precio de cinco velos castellanos. ACA, RP, 478, fol. $56 \mathrm{v}$.

${ }^{1+2}$ Véanse, respectivamente, reg. cancillería 914 . fols. $136 \mathrm{v}-137 \mathrm{r}$ y 2041 . fols. $40 \mathrm{v}-41 \mathrm{r}$. Véase también ACA, reg. cancillería 916, fols. 136 v-137 r (año 1366) y 803, fols. 16-16 v (1379. VIII.6).

${ }^{143}$ Asunción BLASCO, La judería de Zaragoza en el siglo XIV, Zaragoza, 1988, pp. 73, 82, 83 y 225.

${ }^{144}$ BLASCO, Jewish and convert, pp. 52-54.

${ }^{145}$ AHPZ, Domingo Martín de Aguilón, 1391, fols. 192 v.-193 rr y 1393.X.30, fols. 113 v. $-114 \mathrm{r}$.

${ }^{1+6} \mathrm{BLASCO}$, Jewish and convert, pp. 53-54.

${ }^{1+7}$ AHPZ, Juan de Capilla, 1405.V.25, 1405.XI.20 y 1405.XII.22.

${ }^{148}$ AHPZ, Juan Doto, 1409.III.5.

${ }^{149} \mathrm{AHPZ}$, Pascual Alegre, 1389.IX.28, fols. $76 \mathrm{r}-76 \mathrm{v}$.

${ }^{150} \mathrm{AHPZ}$, Juan Blasco de Azuara, 1394, fols. 140 v.-141 r. De su actividad como juglar me ocupé ampliamente en BLASCO, Jewish and convert. pp. 52-53.

${ }^{15 !} \mathrm{AHPZ}$, Domingo Martín de Aguilón, 1390, fols. 25 r-25 v. Sobre sus casas, véase Blasco, La judería, p. 88.
} 
Surí, Jucé: en la década de los años 40 residía en Zaragoza ${ }^{152}$. Veinte años después, Jucé Surí, "corredor de ropa" recibía de Mateo Molet el encargo de buscar comprador para una cinta de plata, que en efecto consiguió vender por 35 florines de oro ${ }^{153}$. En 1361 fue testigo de Salomón Abnarrabí y colaboró con Mossé Alazar, hijo de Ezdra, por lo que fue remunerado ${ }^{154}$.

\subsection{Corredores de libros}

A lo largo del siglo XIV la burguesía ciudadana alcanzó una posición cultural, social y económica que le permitía coleccionar libros, privilegio hasta entonces reservado a las instituciones eclesiásticas y a la clase principesca y aristocrática. Estos nuevos ricos dirigían sus preferencias hacia los libros tradicionales de oración (breviarios) y Biblias, aunque se observa en ellos una marcada afición por las obras jurídicas y médicas escritas en lengua vernácula. En el marco descrito, se afianza la figura del corredor de libros, fruto y promotor a un tiempo de este movimiento favorable a la obra escrita. Algunos judíos de Zaragoza descollaron en el comercio del libro, quizás por poseer cierto nivel intelectual y, sobre todo, porque poseían un buen espíritu comercial, capaz de arriesgar una fuerte suma a cambio de algo tan novedoso y exquisito como un bello libro.

Aunque algunos desempeñaron otras tareas relacionadas con el mundo del libro manuscrito, figuran documentados como corredores de libros los judíos siguientes: Simeón Albalá, Mossé Deulocrega, Salomón Moheb y Salomón de Salinas. También se dedicaron a ello algunos conversos, como Juan de Laporta y Juan Sánchez de Calatayud, hijo de Alazar Golluf, al que me referiré más adelante. He aquí una pequeña biografía de cada uno de ellos:

${ }^{152}$ AHPZ, Pedro Sánchez de Monzón, 1342.IX.12.

${ }^{153}$ 1360.III.27.- Mateo Malet, juglar de la Reina, absuelve a Sancho Sánchez de Pardina, vecino de Zaragoza, que había salido fiador de Jucé Surí, "corredor de ropa de la dita ciudat" a quien Mateo le había entregado una cinta de plata para que la vendiera. El judío la había vendido por 35 florines que ya estaban en poder de Mateo. AHPZ, Simón de Capilla, 1360, fols. $117 \mathrm{r}-117 \mathrm{v}$.

${ }^{154} \mathrm{AHPZ}$, Sancho de Jaca, 1361.VIII.27 y I.31. 
Albalá, Simeón: aparece registrado como corredor de libros en un acta notarial de 1389 en la que se conserva su firma autógrafa ${ }^{155}$. Era hijo de Mira la Madrina, que casó en segundas nupcias con Jehudá Leví, también corredor ${ }^{156}$. En la década de los años 90 se le llamaba el "mayor de días" (para diferenciarle de algún homónimo) y era corredor público de la aljama ${ }^{157}$. Desde 1396 le suelen respaldar en las obligaciones de préstamo y comanda su mujer, Astruga Vilforat, y su madre, Mira ${ }^{158}$. Habitaba en unas casas de su propiedad situadas en la judería de Zaragoza ${ }^{159}$.

Deulocrega, Mossé: además de rabí, era "corredor publico de livros de la ciudat de Çaragoça" y encuadernador. Proporcionó libros litúrgicos latinos a individuos que en ocasiones procedían de lugares lejanos: tal aconteció con Pedro de Zamora, del reino de Castilla, que en 1396 le compró un breviario del rito romano, de pergamino, encuadernado en seda de color rojo y verde, por 9 florines de oro ${ }^{160}$.

Moheb, Salomón era hijo del sastre Jehudá Moheb, posiblemente originario de Valencia ${ }^{161}$ aunque desde 1359 está documentado en Zaragoza, donde seis años después estuvo preso en el monasterio de los Dominicos de Zaragoza "por feyto de Inquisicion"162. Desde 1384 Salomón intervino en numerosas cartas de préstamo a mudéjares, cristianos y conversos ${ }^{163}$. Menos frecuentes, aunque más sustanciosos, fueron los préstamos y

\footnotetext{
${ }^{155} \mathrm{AHPZ}$, Vicente Rodiella, 1389, fols. 348 v. -349 r.

${ }^{156}$ Véase AHPZ, Juan Blasco de Azuara, 1396, fol. 159 v. y Juan Doto, 1396, fol. 12 r.

${ }^{157} \mathrm{De}$ su actividad como andador de la aljama me ocupo en otro estudio.

${ }^{158}$ AHPZ, Juan Blasco de Azuara, 1396, fol. 189 v.

${ }^{159}$ Blasco, La judería, p. 91.

${ }^{160} \mathrm{AHPZ}$, Juan Blasco de Ażuara, 1396, fol. 242 bis v.

${ }^{161}$ En 1363 residía en Valencia Salomón Moheb, posiblemte padre de Jehuda y, en consecuencia, abuelo de Salomón (BAER, JCS, I, p. 379).

${ }^{162}$ Asunción BLASCO, La Inquisición y los judios en Aragón en la segunda mitad del siglo $X I V$, en "Aragón en la Edad Media. Estudios de Economía y Sociedad", VII (1987), pp. 85-86 y $91-92$.

${ }^{163}$ AHPZ, Juan López de Barbastro, 1375, fol. 2 v. A modo de ejemplo, véanse AHPZ, Domingo Martín de Aguilón, 1384, fol. 18 r, 1384.IV.6, fols. 159 v.-160 r y AHPZ, Juan Blasco de Azuara, 1390, fol. 50 v.
} 
comandas recibidos por él: sea solo ${ }^{164}$, con su padre ${ }^{165}$, con su esposa Floria Francés ${ }^{166}$ o con otros correligionarios ${ }^{167}$.

No se sabe de donde le venía la afición por los libros, aunque es fácil que guardara relación con las aficiones de su padre y que la encarcelación de éste, por orden de la Inquisición medieval, también tuviera que ver con esto. Lo cierto es que Salomón aparece registrado como "corredor de livros" de Zaragoza por vez primera en 1389, aunque seguramente ejercía el oficio ya antes ${ }^{168}$. Desde entonces continuó desempeñando el oficio, que al parecer compaginó con el de escritor de libros ${ }^{169}$. En febrero de 1390 intervino como "corredor publico de liuros de la dita ciudat" en la transacción de "un liuro clamado Biblia en romanz et en ebrayco yes clamada Machdexia (sic), la qual Biblia yes cubierta de cubiertas de cuero bermello cozido et obrado et yes guarnida en los encerramientos de cabos et tachones de argent" entre el converso Juan Sánchez de Calatayud (vendedor) y Jehudá Alulayech ${ }^{170}$ (comprador), judío de Valencia, que le entregó 75 florines de oro por el citado códice, escrito "en hebrayco siquiere de letra hebray$\mathrm{ca}^{171}$. Su relación con esa ciudad levantina se incrementó antes de los desastres de 1391 y prueba de ello es que, según apunta Olmos y suscribe Rubiò, el ms. 133 de la Catedral de Valencia (la Summa de Vitiis del religioso dominico Guillermo de Perault, de Loduno), escrito en vitela, a dos

\footnotetext{
${ }^{164}$ AHPZ, Juan Blasco de Azuara, 1392, fol. 428 r, 1393, fols. 244 r, 742 v. y 1395, fols. 94 v. y 605 v, y Juan Doto, 1397, fol. 27 r.

${ }^{165}$ Blasco, La Inquisición, p. 86.

${ }^{166} \mathrm{AHPZ}$, Juan Blasco de Azuara, 1390, fol. 52 v, Domingo Martín de Aguilón, 1391.X.12, Pascual Alegre, 1397, fols. 29 r-29 v. y Juan Blasco de Azuara, 1400, fols. 5 v. -6 r.

${ }^{167}$ AHPZ, Pascual Alegre, 1389, fols. 76 r-76 v.

${ }^{168} 1389$.XI.22. Salomón Moheb, corredor de libros, judío de Zaragoza, recibe 50 sueldos en comanda de Juan de Linas, rector de Villafranca (AHPZ, Vicente Rodiella, 1389, fols. 348 v.-349 v). En 1387 el infante Martín, a ruegos de Salomón Moheb, corredor judío de Zaragoza, encargaba al Zalmedina de la ciudad que hiciera las averiguaciones oportunas y procediera en consecuencia, pues Ramón de Torrellas, de esa misma ciudad, al parecer no había cumplido los acuerdos suscritos con el citado Salomón (ACA, reg. cancillería 2081, fol. 4 r).

${ }^{169}$ Jordi RUBIÓ I BALAGUER, Impremta i llibreria a Barcelona (1474-1553) Diputació de Barcelona, 1986, p. 32 (nota 84).

${ }^{170}$ Seguramente se trata de Jehudá Alolaeg, domiciliado en Valencia en 1363 (BAER, JCS, I, p. 379).

${ }^{171}$ AHPZ, Juan Blasco de Azuara, 1390, protocolo, fol. 42 v y registro, fols. 160v.-163r.
} 
columnas y con las letras capitales y los calderones en color rojo y azul, fue adquirido en 1991 por Raymundo Francés, gracias a su mediación ${ }^{172}$

El resultado de estas operaciones no siempre resultó satisfactorio para él, debido a la morosidad de algunos de sus clientes. Tal aconteció con un letrado de Calatayud, llamado Juan Ibáñez, que en mayo de 1398 le seguía debiendo 18 florines de oro y 5 sueldos jaqueses por "diez y ocho çisternos de Barthol de Sasso Ferrato" que le había proporcionado hacía cinco años, concretamente en febrero de 1393, por lo que Salomón presentó una reclamación ${ }^{173}$. Tuvo tratos mercantiles con el corredor Juan Sánchez de Calatayud y con Gil Aznárez de Latorre, judeoconversos ${ }^{174}$. Formó parte del organismo ejecutivo de la aljama y perteneció a la cofradía de Bicorolim $^{175}$. Sus casas se hallaban en el callizo de Chevamillos, no lejos del muro de piedra ${ }^{176}$. Tanto él como su mujer, Floria, tuvieron larga vida: en 1415 residían en Zaragoza y desarrollaban intensa actividad financiera ${ }^{177}$.

Salinas, Salomón de: era hijo de Abraham, que fue notario o sofer de la aljama de Zaragoza ${ }^{178}$. Su vida se desarrolló por tanto en un entorno cultural muy superior al de la media de sus correligionarios. No es de extrañar que sus actividades giraran en torno al libro, tanto a su elaboración como a su venta. Como corredor, trabajó para judíos y cristianos: así, en febrero de 1409 saldaba cuentas y reconocía ante notario que había recibido de Jaime Bulo de Nápoles, escribano de "letra forana" (de fuera del país) domiciliado en la citada ciudad y ejecutor testamentario de Gausselmo Ros, clérigo difunto, el encargo de vender al mejor postor "vint et seys quadernos

\footnotetext{
${ }^{172}$ Elias Olmos y Canalda, Códices de la catedral de Valencia, Madrid, 1943, n 133 , pp. 102-103. Recoge la noticia RuBió, Impremta, p. 32 (nota 84).

${ }^{173}$ AHPZ, Juan Blasco de Azuara, 1393.X., fol. 592 v. y 1398, fols. 390 v.-391 r. Se refiere a Bartolo de Sasso Ferrato, jurista boloñés de gran renombre en Europa (Jocelyn HILlgaRTH, Readers and books in Majorca, 1229-1550, I, Paris, CNRS, 1991, pp. 85-86).

${ }^{174}$ AHPZ, Pascual Alegre, 1389, fols. 76 r-76 v. y Juan Blasco de Azuara, 1393, fols. 243 $\mathrm{r}-243 \mathrm{v}$

${ }^{175}$ AHPZ, Juan Blasco de Azuara, 1399.II.4, fol. 113 v.

${ }^{176}$ BLASCO, La judería, pp. 65, 72, 73, 75 y 76.

${ }^{177} \mathrm{AHPZ}$, Martín de Tarba, 1415, fols. $284 \mathrm{r}-288 \mathrm{v}$.

${ }^{178}$ Sobre los notarios de la aljama de Zaragoza, véase Asunción BlASCO, Notarios-Escribanos judíos de Aragón (siglos XIV-XV), en "Rashi 1040-1990" (=Hommage à Ephraïm E. Urbach), Paris, Cerf, pp. 645-656.
} 
de Missal mixto ${ }^{179}$ por illuminar et por rubricar", que finalmente adquirió Jaime Matutano, racionero difunto de la Seo de Zaragoza, por 15 florines de oro. Asimismo, confirmó haber recibido del mencionado Jaime, en concepto de depósito, "hun breviario" que también había vendido por 8 florines $^{180}$. Como encuadernador, en 1412 Salomón recibía 16 sueldos jaqueses del tesorero del rey por cinco libros que había realizado para esa tesorería: tres con cubiertas de cuero y dos de pergamino ${ }^{181}$.

Entre los corredores de libros registrados en Zaragoza durante los últimos años del siglo XIV figuran, además, los conversos Juan de la Porta, cuya filiación judía de momento se desconoce ${ }^{182}$, y Juan Sánchez de Calatayud (antes Açach Golluf), que intervino en la compra de códices diversos $^{183}$, aunque según parece la correduría de libros no era su especialidad.

\subsection{Corredores de animales}

Los corredores de "bestias" intervenían en las operaciones de compraventa de animales, especialmente caballos y animales de carga ${ }^{184}$. Podían participar en las subastas a requerimiento del dueño del animal ${ }^{185}$.

En 1343 Mossé Leví, junto con Domingo Andrés de Serra, Pascual de Martes, Eximeno de Aviego y García Gil de España constituían en Zaragoza un grupo o compañía "al officio de correduria de bestias" por un periodo de catorce meses ${ }^{186}$. En el siglo $\mathrm{XV}$, el número de los corredores de animales de esa ciudad se circunscribía a seis, entre los que se supone que

\footnotetext{
${ }^{179}$ Posiblemente se refiere a la mezcla en un misal plenario de los libros que servían para la misal y el oficio. Véase el Diccionario de Historia Eclesiástica de España (dir. por Q. Aldea, T. Marín y J. Vives), II, Madrid, 1972, p. 1309-1310 y 1323-1324.

${ }^{180} \mathrm{AHPZ}$, Juan Blasco de Azuara, 1412, fol. $146 \mathrm{v}$.

${ }^{181} \mathrm{ACA}, \mathrm{RP}, 415$ (septiembre). Recoge la noticia RuBió, Impremta, p. 33 (nota 87), que leyó Çalives en lugar de Salins. Quiero agradecer a Jaume Riera i Sans, del ACA, que me comunicó esta noticia y que me ha facilitado la consulta de éste y otros documentos del ACA utilizados en el presente trabajo.

${ }^{182}$ AHPZ, Juan López de Barbastro, 1393, fols. 86 r-87 v. $167 \mathrm{v}$

${ }^{183} \mathrm{AHPZ}$, Rodrigo Alfonso, 1381, fols. 83 r-83 v y Juan López de Barbastro, 1393, fol.

${ }^{184}$ Ibid.

${ }^{185}$ AHPZ, Pedro Aznárez de Ansó, 1362, fol. 7 v.

${ }^{186}$ AHPZ, Pedro Serra, 1343, fols. 102 v-103 r.
} 
había judíos ${ }^{187}$. En el siglo XIV ejercieron el oficio de corredor de animales de Zaragoza los judíos siguientes: Jentó Abdoxar, Salomón Abenlopiel, y Abraham Toledano.

Abdoxar, Jentó: estaba casado con Oro Ceti ${ }^{188}$ y a finales del siglo XIV se le llamaba "el mayor" 189 para diferenciarle de un homónimo, casado con Bellita, y apodado "el menor"190. Se asoció con el latonero Jucé Zen para comprar carbón de humo ${ }^{191}$; pero su especialidad era la de corredor de caballos ${ }^{192}$. En los protocolos notariales de la época se conserva su firma autógrafa en caracteres hebreos ${ }^{193}$. Aunque no he conseguido averiguar qué lazos de parentesco le unían con Mossé Abdoxar, al morir éste, Jentó heredó unas casas situadas en el callizo del Arco de don Junez de la judería nueva ${ }^{194}$.

Abenlopiel, Salomón: residía en Zaragoza y en 1355 gozaba de plena personalidad jurídica ${ }^{195}$. En 1362 se encargó de subastar una mula de pelo castaño oscuro, con frenos, silla y cabestro, a iniciativa de Diego de Soria, dueño del animal ${ }^{196}$. Documentado como testigo en diversas ocasiones, acudia a las asambleas plenarias de la comunidad, de la que en 1367 fue adelantado y posteriormente consejero ${ }^{197}$.

Toledano, Abraham: documentado en Zaragoza desde 1355, aparece registrado en un acta notarial del 5 de abril de 1381 como deudor de Guillem de Ferrera, escudero de Barcelona, junto con Samuel Abenforna, judío de Teruel: con tal motivo, se hace constar que era "corredor de bestias"198

\footnotetext{
${ }^{187}$ FALCÓN, Notas sobre los corredores, p. 189.

${ }^{188} \mathrm{AHPZ}$, Juan López de Barbastro, 1393, fol. $167 \mathrm{v}$.

${ }^{189}$ AHPZ, Domingo Martín de Aguilón, 1395, fol. $184 \mathrm{v}$.

${ }^{190} \mathrm{AHPZ}$, Domingo Martín de Aguilón, 1397, fol. 156 v. y 1398, fol. 3.

${ }^{191}$ AHPZ, Juan Blasco de Azuara, 1395, fol. 676 v.

${ }^{192}$ AHPZ, Domingo Martín de Aguilón, 1391, fols. 13 v-14 r, Juan López de Barbastro, 1393, fol. 167 v y Juan de Capilla, 1406, fols. 151 v-152 r.

${ }^{193} \mathrm{AHPZ}$, protocolo de Miguel de Canfranc de 1392, fol. $46 \mathrm{r}$.

${ }^{194}$ BLAsCo, La judería, p. 245.

${ }^{195}$ AHPZ, Sancho de Ejulve, 1355, fol. 103 v.

${ }^{196} \mathrm{AHPZ}$, Pedro López de Ansó, 1362, fol. $7 \mathrm{v}$.

${ }^{197}$ AHPZ, Sancho de Jaca, 1361, fols. 69 r-70 r, Domingo Pérez de Acelín, 1367, fol. 204 v. y Domingo Pelagut, 1380, II.2.

${ }^{198}$ AHPZ, Sancho de Ejulve, 1355.X.8 y Rodrigo Alfonso, 1381, fols. 83 r-84 r y 197 v.
} 


\subsection{Corredores de corambre}

Unicamente he registrado en Zaragoza la presencia de un corredor de corambre: se trata de Abraham Calahorrano, que en 1395 participaba en la compraventa de pieles ${ }^{199}$. Esta penuria de datos me ha impedido ver su posible relación, si es que la había, con asociaciones sociolaborales de zapateros, baldreseros y pellejeros judíos ${ }^{200}$.

\subsection{Corredores (sin especificar)}

En la documentación notarial son numerosas las citas de judíos a quienes se da la denominación de "corredor" sin que se añada una mención de actividad que se refiera a su función específica. A menudo se tiene la impresión de que se trata de andadores o pregoneros al servicio de los adelantados, que suelen aparecen registrados como "corredor de la aljama" o "corredor de la juderia"201. Pero otras veces parece clara su intervención en operaciones comerciales y con frecuencia se diría que combinan las dos actividades. Ante estas dudas, he considerado lo más oportuno agrupar aquí a todos estos judíos, de los que trato por orden alfabético, recogiendo cuantos datos puedan interesar a su biografía, en un intento de fabricar un cañamazo que sea de utilidad para futuras aclaraciones y confirmaciones o bien facilite la posibilidad de decidir su exclusión del grupo de corredores. $\mathrm{XV}^{202}$.

Abenforna, Salomón, corredor en Zaragoza a comienzos del siglo

Albelda, Jehudá: poco podemos decir acerca de este individuo, documentado en Zaragoza en 1389 como corredor ${ }^{203}$. En 1390 el especiero Nicolás Sarrel le dejaba en comanda "hun cofret cubierto de cuero de buey, forrado, en el qual dentro son IX enbaxas siquiere joyas, las quales lievan judias en las cabeças et por collares, guarnidas de perllas et argent", quizás

\footnotetext{
${ }^{199}$ AHPZ, Juan López de Barbastro, 1395.III.9.

${ }^{200}$ BlasCo, Instituciones, pp. 40-45.

${ }^{201}$ De ellos me ocupé ampliamente en el cap. II de mi tesis doctoral sobre Los judios de Zaragoza en el siglo XIV, Zaragoza, 1987. Inédito.

${ }^{202} \mathrm{AHPZ}$, Juan de Capilla, 1407, fol. $68 \mathrm{r}$.

${ }^{203} \mathrm{AHPZ}$, Domingo Martín de Aguilón, 1389, fols. 26 r-26 v.
} 
para que procediera a su venta ${ }^{204}$, lo que induce a pensar que tal vez era corredor de ropa.

Abenafión ${ }^{205}$, Abraham: en 1397 era corredor público de la aljama y "andador", pero además ejercía el oficio de corredor ${ }^{206}$, según consta en un contrato de compraventa realizado en Zaragoza el 1 de febrero de 1396, en virtud del cual Miguel de Bailo, vecino de Alcañiz, "present Abraym Abenafiyon, jodio corredor de la aljama de los jodios de Çaragoça", vendió a Jucé Alazar, judío de dicha ciudad, "una [cinta] dargent mia guarnida en tella de seda morada, a esmaltes et boletes, sobredorada en savastre con cabos smaltados, en el huno ha scripto amor mercese et en el otro amor", por 19 florines de oro $^{207}$; por lo que también en este caso me inclino a pensar que fue corredor de ropa.

Abenardut, Salomón: a comienzos del siglo XV aparece registrado como corredor de Zaragoza ${ }^{208}$. Parece ser que era hijo de rabí Jacob, pues a finales del siglo XIV y comienzos del XV vivían en Zaragoza dos homónimos.

Alcarahuey, Zecrí: comenzó su actividad en las postrimerías del siglo XIV. La primera noticia sobre dicho personaje data de 1395 y me consta que en los primeros años del siglo XV era corredor en Zaragoza ${ }^{209}$.

Alheibarí, Astruch: en 1328 se hallaba domiciliado en Zaragoza y era corredor ${ }^{210}$.

Almalcavi $^{211}$, Jacob: figura como acreedor en numerosas actas de préstamo. En 1381 ostentaba el cargo de adelantado ${ }^{212}$, lo que no le impidió proseguir su actividad negociadora y de prestamista con algunos cristianos de la ciudad, entre los que cabe destacar al pintor Guillén de Leví $^{213}$, así como con mudéjares de diferentes lugares de Aragón ${ }^{214}$. En

\footnotetext{
${ }^{204}$ AHPZ, Juan Blasco de Azuara, 1390, protocolo, fol. $136 \mathrm{r}$

${ }^{205}$ Además de esta grafía, se dan las de "Jafion" y "Jahihon".

${ }^{206} \mathrm{AHPZ}$, Pedro de Carlos, 1399, fol. 127 v.

${ }^{207} \mathrm{AHPZ}$, Domingo Martín de Aguilón, 1396.II.10, fol. 39 r.

${ }^{208}$ AHPZ, Juan de Capilla, 1405.XI.20 y 1406, fol. 206 v.

${ }^{209} \mathrm{AHPZ}$, Juan López de Barbastro, 1395, fols. $26 \mathrm{v} .-27 \mathrm{r}$ y 1414, fol. $110 \mathrm{v}$.

${ }^{210} \mathrm{AHPZ}$, Domingo de la Figuera, 1328.IX.16.

${ }^{21}$ "Esta grafía, que es la más frecuente, coexiste con las de "Alcavi" y "Abenalcavit".

${ }^{212}$ Sancho Martínez de la Peira, 1381, fols. 187 r-188 v.

${ }^{213}$ AHPZ, Rodrigo Alfonso, 1384, fol. 182 r. Véase Asunción BLASCO, Pintores y orfebres judios en Zaragoza (siglo XIV), "Aragón en la Edad Media", VIII (1989), p. 119.
} 
1389 se solidarizó con rabí Açach Abulfada y con el corredor de número Mossé Afia para solicitar a Botín del Bosch 675 sueldos jaqueses en comanda, que no fueron devueltos hasta quince años después ${ }^{215}$. En 1394 comerciantes de tejidos de Zaragoza recabaron sus servicios para que tasara el valor de varias partidas de paños ingleses, recién importadas, que presentaban taras diversas ${ }^{216}$. Poco después le sobrevendría la muerte, pues el 18 de agosto de ese mismo año su mujer, Mira de Juliciel, que le había dado un hijo llamado Salomón, se declaraba viuda ${ }^{217}$.

Arama, Jucé: hijo de Gadella, en 1355 era corredor de Zarago$\mathrm{za}^{218}$. Disfrutó de la franquicia que el rey don Pedro le había otorgado hasta que el 20 de marzo le fue revocado el privilegio, al igual que a otros judíos de la aljama ${ }^{219}$. Poseía unas casas en el callizo de Medio de la judería nueva ${ }^{220}$.

Asayuel, Salomón: era hijo de Azmel y de Aliofar ${ }^{221}$. Residía en Zaragoza, pero hasta 1405 no se constata que fuera corredor ${ }^{222}$. Entre 1393 y 1396 intervino en diversas transacciones comerciales, generalmente de paños ${ }^{223}$, lo que no es de extrañar porque su padre era destacado pañero de la ciudad. Estaba casado con Astruga, que le respaldó en algunas de sus obligaciones crediticias ${ }^{224}$.

Baruch, Alazar: en la última década del siglo XIV era corredor público de la aljama, andador o pregonero de los adelantados y albedín ${ }^{225}$. En 1397 intervino en la venta de una "hopa" de Juan de Ejulve, que fue

\footnotetext{
${ }^{214}$ AHPZ, Domingo Martín de Aguilón, 1391.II.20, fols. 37 r-37 v.

${ }^{215} \mathrm{AHPZ}$, Juan Blasco de Azuara, 1389, fol. 260 v. y 1395, fol. $181 \mathrm{r}$.

${ }^{216} \mathrm{De}$ esto me ocupo en un estudio que actualmente preparo.

${ }^{217}$ AHPZ, Domingo Martín de Aguilón, 1394. VIII.18, fols. 59 r-59 v.

${ }^{218} \mathrm{AHPZ}$, Sancho de Ejulve, 1355.XI.24.

${ }^{219} \mathrm{ACA}$, reg. cancillería 2206, fols. 86 r-88 r (1360.III.20).

${ }^{220} \mathrm{BLASCO}$, La judería, p. 115.

${ }^{221}$ AHPZ, Domingo Martín de Aguilón, 1396, fol. 4 r y 1393, fol. 164 v.

${ }^{222}$ AHPZ, Juan de Capilla, 1405, fol. 220 v.

${ }^{223}$ AHPZ, Domingo Martín de Aguilón, 1393.XI.1, 1394.II.25 y 1396.

${ }^{224}$ AHPZ, Domingo Martín de Aguilón, 1394.II.9.

${ }^{225} \mathrm{De}$ su actividad como andador me ocupo en otro trabajo.
} 
comprada por Jacob Tuli, judío de dicha ciudad ${ }^{226}$, por lo que cabe pensar que su especialidad sería la de corredor de ropa,

Capacho, Mossé: también llamado "Capag", a comienzos del siglo XV desempeñaba el oficio de corredor ${ }^{227}$.

Cidillo, Samuel: se constata su presencia en 1376 en Zaragoza de donde se dice que era corredor ${ }^{228}$.

Cohén, Abraham: en 1340 está documentado como corredor de Zaragoza ${ }^{229}$.

Crescas, Samuel: era nieto de Reina Hasday y, como ella, procedía de Barcelona. Al final de la década de los 80 se trasladó a Zaragoza, ciudad en la que se hallaba domiciliado en 1389-90. Allí ejerció el oficio de corredor, al tiempo que intervenía activamente en la vida pública de la aljama $^{230}$

Feduchal, Azmel: miembro de la aljama de Zaragoza bien conocido por su gran actividad en el mundo de los negocios ${ }^{231}$, en 1384 fue investigado por orden del infante Juan a raíz de cierto litigio suscitado entre él y otros judíos de la comunidad ${ }^{232}$.

Gadella, Jucé: en 1367 este corredor judío de Zaragoza percibió del tesorero del Rey la asignación correspondiente a los servicios prestados. Fue denunciado por Mayr Alazar y en 1371 ajusticiado por delator ${ }^{233}$.

Golluf, Açach: hijo de don Alazar Golluf y nieto del pañero Açach, en la década de los años 80 gozaba de personalidad jurídica y se le llamaba

\footnotetext{
${ }^{226}$ Domingo Martín de Aguilón, 1397, fol. 65 r.

${ }^{227}$ AHPZ, Juan de Capilla, 1405.X.8 y 1406, fols. 11 v-12 r.

${ }^{228} \mathrm{AHPZ}$, Sancho Martínez de la Peira, 1376.XI.3.

${ }^{229} \mathrm{AHPZ}$, Tomás de Batalla, 1340, fols. $31 \mathrm{r}-31 \mathrm{v}$.

${ }^{230} \mathrm{AHPZ}$, Juan de Capilla, 1405.V.7. Intervino en numerosas transacciones entre las que cabe destacar una de 1399 en la que su cliente, cristiano, le acusó de haber cometido fraude (AHPZ, Domingo Martín de Aguilón, 1395.V.28, fol. 91 v.).

${ }^{231}$ Fue arrendador de la sisa del brazaje de la aljama en 1389 (AHPZ, Juan Blasco de Azuara, 1389, fol. 474) y consejero de la misma en 1399 (AHPZ, Domingo Pelagut, 1399.XII.7).

${ }^{232}$ En la misiva que el Infante envió a Salomón de la Cavallería y al maestro Junez Trigo, judíos de Zaragoza, para que se hicieran cargo de la investigación, se refiere a "Azmel Feduxal, aliter vocatum corredor, judeum Cesarauguste". ACA, reg. cancillería 840 , fol. $41 \mathrm{v}$. (1384.V.20).

${ }^{233}$ Asunción BLASCO, Los malsines del reino de Aragón, "Eleventh World Congress of Jewish Studies", Jerusalem 1993, p. 89.
} 
el menor para diferenciarle de su abuelo ${ }^{234}$. Pertenecía a la clase aristocrática de la aljama, pero en torno a 1389-90 se convirtió al cristianismo adoptando el nombre de Juan Sánchez de Calatayud ${ }^{235}$. Fue corredor de comercio en Zaragoza ${ }^{236}$.

Golluf, Jehudá: hijo asimismo de don Alazar Golluf ${ }^{237}$ y, por lo tanto, nieto de Açach y hermano del anterior y de otro judío llamado Abraham. Intervino activamente en la vida pública de la comunidad: solía asistir a las reuniones de la aljama, de la que fue consejero. En 1397 obtuvo en arriendo la percepción de algunos impuestos y en 1400 fue nombrado clavario ${ }^{238}$. Supo combinar su participación en la dirección de los asuntos de la comunidad con una notable actividad en el mundo de los negocios. En 1395 era corredor: como tal intervino en la devolución de ciertas prendas que su hermano Abraham había recibido de un cristiano así como en numerosas transacciones comerciales ${ }^{239}$. Todavía no he conseguido averiguar por qué en 1394 renunció a la parte que le correspondía en la herencia de su abuelo Açach en beneficio de su hermano Abraham, al que según parece se hallaba estrechamente vinculado ${ }^{240}$.

Gotina, Jentó: en 1373 era corredor de la aljama ${ }^{241}$.

Jahiel, Azmel: en 1388 residía en Zaragoza de donde era corre$\operatorname{dor}^{242}$.

Leví, Jehudá: entre 1362 y 1410 fue corredor de la aljama de Zaragoza $^{243}$. Además, intervino activamente en diversas operaciones transaccionales ${ }^{244}$.

${ }^{234}$ AHPZ, Domingo Martín de Aguilón, 1385.III.22 y 1385.X.3.

${ }^{235}$ BAER, JCS, I, n. 390.

${ }^{236}$ AHPZ, Domingo Martín de Aguilón, 1402, fols. 28 v-29 r.

${ }^{237}$ Estoy realizando un estudio sobre este personaje, que fue tesorero de la reina Violante.

${ }^{238} \mathrm{AHPZ}$, Jimeno de Alberuela, 1397, fols. 65 v-66 r.

${ }^{239}$ AHPZ, Ramón Amat, 1395, fols. 202 v.-204, Domingo Martín de Aguilón, 1396, fol. 63 r y 1397, fol. 72 r y Juan López de Barbastro, 1400, fols. 161 v.-162 r.

${ }^{240}$ AHPZ, Ramón Amat, 1395, fols. 202 v.-204 r y Domingo Martín de Aguilón, 1395.II.8.

${ }^{241}$ AHPZ, Blasco Aznárez de Ansó, 1373, fol. 38 v.

${ }^{242} \mathrm{AHPZ}$, Miguel de Canfranc, 1388, protocolo, fol. $29 \mathrm{v}$.

${ }^{243} \mathrm{AHPZ}$, Blasco Aznárez de Ansó, 1362, fols. 72 r-72 v y Juan de Capilla, 1410, fols. 3 $\mathrm{v}-4 \mathrm{r}$.

${ }^{244} \mathrm{AHPZ}$, Vicente Rodiella, 1375, registro, fols. $100 \mathrm{r}-100 \mathrm{v}$. 
Pazagón, Abraham: aunque seguramente era originario de Calatayud, en las postrimerías del siglo XIV residía en Zaragoza, donde ejercía el oficio de corredor ${ }^{245}$. Aparece registrado como procurador y testigo en numerosas actas notariales suscritas por sus correligionarios, en una de las cuales se conserva su firma autógrafa en caracteres hebreos ${ }^{246}$.

Sol: esta "corredora", cuyo nombre de familia no he conseguido determinar, en 1356 residía en Zaragoza, donde desempeñaba el oficio. Entabló negociaciones con Pero Martínez de Ansó y con su mujer, quienes le dejaron en prenda "una corona dargent con piedras et quinze cullaretas dargent 247 .

Trigo, Jucé: que era corredor en Zaragoza en $1405^{248}$.

\section{CONCLUSIONES}

A lo largo del siglo XIV se observa cierto intrusismo en el ejercicio del oficio de corredor, pero no sólo por parte de gentes que sin ser corredores actuaban como tales (según se ha demostrado para la segunda mitad del siglo XV), sino también por parte del poder real, empeñado en controlar un oficio que solapadamente considera equiparable al notariado, pues como aquél implica fe pública.

No hubo judíos que fuesen miembros de la cofradía de Santa María de los Predicadores o de los Mercaderes. Respecto a la proporción de judíos entre los corredores del número mayor de Veinte, se mantuvo la ratio de 6 judíos y 14 cristianos que se había establecido en el siglo XIII. Conforme fue avanzando el siglo $\mathrm{XV}$, se observa una disminución en el número de corredores judíos y un incremento de participación judeoconversa en el mundo del comercio, pues fueron muchos los conversos que se incorporaron a estas tareas como nuevos cristianos: es el caso de Pedro y Lorenzo de Casafranca (antes Abenardut), Jaime Ram (antes Abenafia), Peregrín de San Juan (antes Jucé Alazar), Pedro de Santa Clara (antes Vitales), Adán de

\footnotetext{
${ }^{245}$ AHPZ, Juan de Capilla, 1402.XII.6.

${ }^{246} \mathrm{AHPZ}$, Domingo Martín de Aguilón, 1399, fol. $38 \mathrm{r}$.

${ }^{247} \mathrm{AHPZ}$, Pedro Loarre, 1356, fols. $2 \mathrm{r}-2 \mathrm{v}$

${ }^{248} \mathrm{AHPZ}$, Juan de Capilla, 1406, fols. $17 \mathrm{v}-18 \mathrm{r}$.
} 
Ortuvia (antes Salomón Gallur), Pedro de Jasa (antes Jentó Gallur) o Luis Boninfant ${ }^{249}$.

\section{RÉSUMÉ}

Dans ce travail l'auteur entreprend l'analyse de la structure du mtier de courtier de commerce parmi les juifs de Saragosse, ville principale du royaume d'Aragon, dans la priode de 1300-1425, et partant de sources notariales et royales (Chancellerie et Patrimoine du Roi). Une fois examin l'essai du Roi pour contrler ce mtier, et explique la notion de courtier et ses fonctions, on aborde l'tude des types diffrents des courtiers (toffes, btail, livres, etc.), et on y joint une biographie concise mais documente des courtiers inscrits dans la ville de Saragosse pendant cette periode.

\section{SUMMARY}

In this article the author analyzes the structure of the commercial agent profession among the jews in Saragossa, the main city of Aragon kingdom, taking as a reference the period time between 1300-1425, and using notarial and Royal sources (Chancillerie and Royal Patrimony) to do it. After considering the king's purpose to control this office, and after explaining the meaning of the brokerage and its functions, she studies the different classes of brokers (clothes, animals, books, etc.), including a brief but well-documented biography of each of the jews brokers registered in Saragossa in that period of time.

\footnotetext{
${ }^{249}$ Los conversos constituyen el objeto de un trabajo que publicaré próximamente.
} 